\title{
PERCEPÇÃO DA SOCIEDADE SOBRE A QUALIDADE DE VIDA E O CONTROLE POPULACIONAL DE CÃES NÃO DOMICILIADOS
}

\section{THE SOCIETY'S PERCEPTION OF THE LIFE QUALITY AND POPULATION CONTROL OF STRAY DOGS}

\author{
Flavio Fernando Batista Moutinho ${ }^{1 *}$ \\ Elmiro Rosendo do Nascimento ${ }^{1}$ \\ Rita Leal Paixão \\ ${ }^{1}$ Departamento de Saúde Coletiva Veterinária e Saúde Pública, Faculdade de Veterinária, Universidade \\ Federal Fluminense, Niterói, RJ, Brasil. \\ ${ }^{2}$ Departamento de Fisiologia e Farmacologia, Instituto Biomédico, Universidade Federal Fluminense, Niterói, \\ RJ, Brasil. \\ *Autor para correspondência - flavio_moutinho@id.uff.br
}

\section{Resumo}

$\mathrm{Na}$ maior parte dos municípios brasileiros há superpopulação de cães não domiciliados, os quais trazem problemas associados à ordem urbana, ao meio ambiente e à saúde coletiva, além de sofrerem maus-tratos. Nesse contexto, vislumbra-se a necessidade do desenvolvimento de ações de controle populacional desses animais. O objetivo do presente trabalho foi conhecer a percepção dos atores sociais, como gestores dos órgãos responsáveis pelas ações de controle, gestores de organizações não governamentais de proteção animal e população em geral em relação à qualidade de vida e o controle populacional dos cães não domiciliados. Foram aplicados questionários estruturados a amostras desses três grupos e os dados foram trabalhados com técnicas de estatística descritiva e comparação de frequência. Os resultados permitiram concluir que a percepção da sociedade sobre o controle populacional e a qualidade de vida desses animais guardam importantes diferenças sob a ótica dos três grupos avaliados, mas apresentam, também, semelhanças importantes, em especial no tocante à percepção sobre a responsabilidade pelo desenvolvimento de ações de controle populacional, à aceitação da utilização de recursos públicos destinados à saúde pública nas ações de controle, à qualificação como grande a densidade populacional e à má qualidade de vida desses animais.

Palavras-chave: cão não domiciliado; controle populacional; percepção social.

\begin{abstract}
In most Brazilian municipalities there is an overpopulation of stray dogs, which causes problems to the urban order, the environment and the public health, in addition to mistreatment to these dogs. In such context we foresee the need of developing actions targeting the population control of these animals. This essay aims at knowing the perception of social actors, such as managers of entities responsible for control actions, managers of NGOs working with animal protection and population in general with respect to the life quality and population control of stray dogs. Questionnaires were used on samples of individuals of these three groups and the data thereof were analyzed with descriptive statistics techniques and frequency comparison. The results allowed us to conclude that the society's perception of population control and life quality of these animals bear important differences under the viewpoint of the three evaluated groups; however, they also bear significant similarities, especially with respect to the perception of the responsibility for the development of population control actions, the acceptance of using public funds intended to public health in control actions, the classification of
\end{abstract}


such population density as large and the poor life quality of these animals.

Keywords: population control; social perception; stray dog.

Enviado em: 15 junho 2014

Aceito em: 27 agosto 2015

\section{Introdução}

As mudanças por que vem passando a sociedade, no sentido de diminuição do tamanho das famílias pela redução da natalidade e novos estilos de vida, vêm levando ao aumento da busca afetiva por cães e gatos de estimação ${ }^{(1)}$. Além disso, animais como os de produção estão relacionados ao interesse econômico por parte das pessoas ${ }^{(2)}$.

Características sociais como baixos níveis educacionais e de saneamento associadas à carência de consciência sanitária por parte da população e à negligência do poder público originam um grande quantitativo de cães não domiciliados, que vivem livremente pelas ruas. A maioria dos municípios do País enfrenta problemas envolvendo animais não domiciliados ${ }^{(3)}$. A necessidade de controle da população de cães não domiciliados justifica-se pelo fato de esses animais trazerem e sofrerem uma série de transtornos, incluindo-se aí questões do cunho da saúde coletiva, de problemas de trânsito, de problemas ambientais e dos maus-tratos ${ }^{(4)}$. Durante muitos anos, houve um predomínio de ações sistemáticas de captura e eliminação destes animais por meio da eutanásia em massa efetuada pelo Poder Público. Como essas ações não resultaram em redução considerável na densidade populacional e, considerando-se ainda aspectos éticos e legais, essa estratégia vem sendo paulatinamente substituída por ações focadas na esterilização em massas dos cães, que é uma das medidas preconizadas atualmente. Acredita-se que, ao atuar sobre a reprodução destes animais, conseguir-se-á, com apoio de ações de educação para guarda responsável e legislação apropriada, o almejado controle da densidade populacional. Nesse contexto, o papel das Organizações Não Governamentais de Proteção Animal é de grande importância ${ }^{(5)}$.

Conhecer a percepção dos atores sociais envolvidos nesse processo, como os gestores dos órgãos responsáveis pelas ações de controle, os gestores de organizações não governamentais de proteção animal e a população em geral, pode propiciar um conhecimento estratégico e fundamental para que o controle seja efetivo e eficaz, pois poderá dar subsídios a ações de caráter educativo com vistas à guarda responsável, pela sensibilização e esclarecimento da população.

\section{Material e métodos}

O presente estudo, de caráter quali-quantitativo, foi desenvolvido em 2012 e 2013, tendo sido submetido ao Comitê de Ética em Pesquisa da Faculdade de Medicina/Hospital Universitário Antônio Pedro da Universidade Federal Fluminense, recebendo o protocolo CEPCMM/HUAP n 248/11, e foi aprovado conforme parecer CAAE 0318.0.258.000-11.

Para a sua realização foram elencados três grupos de atores sociais envolvidos, direta ou indiretamente, com a questão do controle populacional de cães não domiciliados, a saber, gestores de serviços de controle de zoonoses (SCZs), gestores de organizações não governamentais de proteção animal e a população de um modo geral.

Foi selecionada uma amostra, composta por 47 dos 92 municípios que compõem o estado do Rio de Janeiro, considerando-se um nível de confiança de 95\% e um erro máximo permitido de 10\%, utilizando-se a fórmula para cálculo de proporções descrita por Thrusfield para amostras com populações finitas ${ }^{(6)}$. Após a definição do tamanho da amostra, esta foi dividida com base no critério 
da amostragem estratificada, de acordo com as dez Regiões de Saúde existentes no Estado ${ }^{(7,8)}$, respeitando-se a proporcionalidade em relação à quantidade de municípios existentes em cada uma delas. Definida a quantidade de municípios a serem pesquisados em cada Região de Saúde, procedeuse à seleção dos mesmos, a qual foi feita por meio de sorteio aleatório simples.

Definida a amostra, foram feitas visitas aos referidos municípios, onde os responsáveis pelos SCZs e pelas ONGs responderam a um questionário estruturado ${ }^{(6)}$, previamente testado, aplicado por profissionais capacitados para a sua aplicação. Os respondentes assinaram, ainda, o respectivo Termo de Consentimento Livre e Esclarecido. Para a questão aberta existente no questionário, com base nas respostas obtidas, foram criadas sete categorias agrupando elementos, ideias ou expressões com similaridades, tendo como base o método da Análise de Conteúdo. As dimensões avaliadas na Análise de Conteúdo foram: maus-tratos, falta de abrigo, falta de cuidado e atenção, deficiência alimentar e adoecimento. Além disso, houve uma dimensão englobando outras respostas encontradas em menor frequência, além da possibilidade de não responder a essas questões.

Os dados obtidos nestes questionários foram codificados, tabulados em planilhas do software Excel $^{\circledR} \mathrm{e}$ analisados com técnicas de estatística descritiva, com comparação de frequências. Posteriormente, foi avaliada a significância estatística pelo teste do qui-quadrado ou teste exato de Fisher, por intermédio do software Bioestat $5.3^{\circledR}$.

Como não foi identificado um cadastro nacional ou estadual de ONGs desta natureza e não foi encontrada, na bibliografia consultada, nenhum trabalho que tenha explorado a base de dados das ONGs de proteção animal para ser tomado como modelo, optou-se por realizar o sorteio a partir das ONGs identificadas após pesquisa no site Google ${ }^{\circledR}$ (www.google.com.br) nas dez primeiras páginas obtidas em busca com o uso dos termos "ONG" + "proteção" + "animal" + "nome do município" + "RJ". O critério de inclusão após o sorteio foi a existência legal da ONG como pessoa jurídica ou com registro em cartório. Importante destacar que somente em 13 dos 47 municípios selecionados foi encontrada, com a metodologia utilizada, ao menos uma ONG de proteção animal, o que equivale a $27,6 \%$ dos municípios. Nas regiões Norte, Noroeste e Metropolitana I, em nenhum dos municípios selecionados foi encontrada ONG de proteção animal. Somente na região da Baía da Ilha Grande foram encontradas ONGs em 100\% dos municípios avaliados.

As ONGs de proteção animal estão enquadradas, de acordo com a rotina de trabalho do IBGE, no grupo das Instituições Sem Fins Lucrativos de Meio Ambiente e Proteção Animal, o qual comportava, em 2010, 2242 organizações ou $0,8 \%$ do total de 290.692 ONGs. A região Sudeste concentrava $50 \%(\mathrm{n}=1124)$ das instituições sem fins lucrativos do grupo naquele mesmo ano ${ }^{(9)}$. De acordo com o $\operatorname{IBGE}^{(10)}$, as regiões fluminenses Norte e Noroeste eram as que tinham menos municípios com a presença de ONGs de meio ambiente e proteção animal, com um município em cada região. Já a Metropolitana I, onde não foi encontrada $\mathrm{ONG}$ em nenhum município pesquisado tinha à época ONGs em 54,5\% dos municípios, mas como o grupo comporta as ONGs de meio ambiente também, isto pode justificar não ter sido encontrada nenhuma de proteção animal.

Para a população em geral foi feito um survey, com abordagem pessoal de transeuntes pelo método intercept, em pontos de grande fluxo populacional, para aplicação do questionário estruturado, previamente testado. Foi selecionada uma amostra composta por 384 indivíduos, considerando-se um nível de confiança de $95 \%$ e um erro máximo de $5 \%$, seguindo o método sugerido por Thrusfield ${ }^{(6)}$. Os critérios de estratificação foram os mesmos utilizados para os outros atores sociais. Os municípios onde foram aplicados os questionários foram sorteados por sorteio aleatório simples, respeitando as Regiões de Saúde.

Os entrevistados desse grupo, cujos critérios de inclusão foram ser morador da Região de Saúde onde estava respondendo ao questionário e maior de 18 anos, foram dispensados de assinar o Termo de Consentimento Livre e Esclarecido por se tratar de uma pesquisa tipo survey em que não há a identificação do respondente, conforme parecer do Comitê de Ética na Pesquisa que a aprovou. O tratamento estatístico foi o mesmo utilizado para os demais grupos de atores sociais. 


\section{Resultados e Discussão}

Em relação à idade dos gestores de SCZs, 80,8\% eram maiores de 30 anos. No que diz respeito à escolaridade, $95,7 \%$ destes tinham nível superior completo e 4,3\% nível médio. Dos gestores de nível superior, $48,9 \%$ eram pós-graduados em nível de especialização, 8,9\% eram pós-graduados em nível de mestrado e 2,2\% eram pós-graduados em nível de doutorado. Não foram encontrados gestores de SCZs não alfabetizados e nem somente com o ensino fundamental. Quanto à formação em nível de graduação dos gestores de SCZs, verificou-se que $80 \%$ eram médicos veterinários, $13,3 \%$ eram biólogos e 6,7\% eram graduados em outra área.

Em relação à idade dos gestores das ONGs de proteção animal, 50\% tinham mais de 50 anos e 28,6\% tinha entre 40 e 50 anos, 21,4\% tinha entre 30 e 40 anos e nenhum era menor de 30 anos. Dos gestores de ONGs, 78,6\% (n=11) tinham formação superior e, destes, 18,2 eram pós-graduados em nível de especialização e $9,1 \%$ em nível de mestrado. Somente $9,1 \%$ destes eram graduados em medicina veterinária. Somente 14,3\% tinham ensino médio e 7,1\% ensino fundamental completo. Não foram encontrados gestores de SCZs não alfabetizados. Em relação ao tempo no exercício da função, 42,9\% estavam há mais de cinco anos, 28,6\% entre um e dois anos, $21,4 \%$ entre dois e cinco anos e 7,1\% há menos de um ano, demonstrando grande aderência à chefia das organizações.

Em relação aos membros da população em geral que responderam ao questionário, os jovens (1830 anos) foram maioria, totalizando $35,1 \%$, seguidos pelos respondentes na faixa etária entre 30 e 40 anos $(25 \%)$, entre 40 e 50 anos $(24,5 \%)$ e maiores de 50 anos $(15,4 \%)$. Entre os membros da população em geral, 85,4\% residiam no mesmo município há mais de cinco anos, 9,6\% entre dois e cinco anos, $3,2 \%$ entre um e dois anos e somente $1,8 \%$ há menos de um ano. Assim sendo, em sua maioria, os cidadãos tinham condições de conhecer a realidade de seu município já que residiam há muitos anos nele. Em relação à escolaridade da população que respondeu ao questionário, a grande maioria (48,2\%) concluíra o ensino médio, 21,6\% o ensino fundamental e 19,8\% o superior. Havia, ainda, $7,6 \%$ não alfabetizados. Dos graduados, 14,5\% concluíram alguma pós-graduação, lato ou stricto sensu.

No que diz respeito às ações de controle populacional desenvolvidas pelo Poder Público, apesar de 46,8\% dos gestores dos SCZs municipais analisados terem informado realizar alguma ação relacionada ao controle populacional de cães não domiciliados, essas ações foram consideradas inexistentes por $57,1 \%$ dos gestores de ONGs e por $47,1 \%$ da população. Foram consideradas insuficientes por 28,6\% dos gestores de ONGs e por $26 \%$ da população. E foram consideradas razoáveis por $14,3 \%$ dos gestores de ONGs e por $11,5 \%$ da população. Somente $2,1 \%$ da população consideraram as ações como boas e $0,3 \%$ como excelentes. Nenhum gestor de ONG considerou como boas ou excelentes as ações desenvolvidas pelo Poder Público Municipal. As diferenças encontradas entre as respostas de gestores de ONGs e população são estatisticamente significativas $(\mathrm{p}<0,05)$.

Não existe uma Política Pública nacional com diretrizes oficiais para o controle populacional de cães não domiciliados no Brasil, o que faz com que muitos municípios negligenciem esse tipo de ação, conforme pode ser observado no presente estudo. Apesar de alguns municípios realizarem algum tipo de ação de controle, estas ações são muitas vezes isoladas e geralmente carentes de avaliação. A situação passa pela má distribuição de recursos públicos e também pela omissão do Poder Público ${ }^{(11)}$. Ao mesmo tempo, a escassez de estudos que consigam associar o controle das populações animais à promoção da saúde humana vem impedindo que políticas públicas sejam criadas e atividades de controle populacional sejam expandidas e regionalizadas ${ }^{(12)}$. Os resultados reforçam a necessidade de que haja políticas públicas em nível nacional a serem desenvolvidas no nível municipal. Essas políticas deveriam contemplar diagnóstico situacional, participação social, desenvolvimento de ações educativas, manejo ambiental, registro e identificação dos cães, cuidados com a saúde e o bemestar animal, prevenção e controle de zoonoses, controle do comércio de cães, destino adequado para os animais abandonados, legislação adequada e prevenção do abandono. O monitoramento com indicadores adequados e a retroalimentação deveriam ser periódicos para que houvesse a avaliação 
dos impactos e para justificar os investimentos na área ${ }^{(13)}$.

Tais políticas deveriam priorizar(14) a eficiência, traduzida pela educação para a guarda responsável e diminuição do abandono; serem humanitárias e justas e serem de responsabilidade compartilhada entre autoridades, profissionais de saúde, educadores, ONGs de proteção animal e cidadãos de maneira geral.

No que diz respeito à representação dos cães não domiciliados para os entrevistados, eles representavam risco à saúde humana para $97,9 \%$ dos gestores de SCZs, mas para somente $64,3 \%$ dos gestores de ONGs e 44,3\% da população em geral. Nota-se claramente uma representação do cão como reservatório de doença preponderantemente na percepção dos gestores de SCZs. A ocorrência das doenças, inclusive das zoonoses, não é apenas uma relação agente x hospedeiro. Outros fatores podem favorecer ou dificultar a infecção. Neste contexto, quanto menor o desenvolvimento local, menores tendem a ser os cuidados sanitários que as pessoas têm em suas relações com os animais ${ }^{(15)}$. A importância do controle destas doenças não pode ser negligenciada e deve-se buscar caminhos que sejam neutros ou mesmo positivos em relação ao bem-estar animal ${ }^{(16)}$. Das doenças infecciosas que afetam os humanos, mais de $70 \%$ podem ser consideradas zoonóticas ${ }^{(17)}$ e este número sobe para $75 \%$ se forem consideradas somente as doenças novas ou emergentes ${ }^{(18)}$.

No que diz respeito ao risco destes animais à integridade física de transeuntes, este foi considerado para $85,1 \%$ dos gestores de SCZs, mas para somente $57,1 \%$ dos gestores de ONG e 39,8\% da população em geral. O risco de acidente de trânsito foi considerado por $85,1 \%$ dos gestores de SCZs e $78,6 \%$ dos gestores de ONGs, mas para somente $53,1 \%$ da população em geral. A quantidade de agressões de cães a humanos é grande no Brasil ${ }^{(19)}$, mas, apesar de boa parte dos participantes de todos os grupos pesquisados terem assinalado o risco à integridade física de transeuntes, ainda que efetivamente este exista, a maior parte das agressões de cães a humanos não envolvem cães não domiciliados e na maioria das vezes envolve o proprietário do animal ${ }^{(20)}$. O relacionamento envolvendo dominância e submissão entre cão e proprietário favorece o risco de agressão ${ }^{(19)}$. Além disso, deve-se considerar que, ainda que não em sua maioria, uma parte considerável das agressões por cães a humanos envolvem algum tipo de provocação pela vítima ${ }^{(21)}$ e a proporção de animais agressores caracterizados como doentes com o comportamento alterado é pequena ${ }^{(19,22)}$.

O risco de sofrimento desses cães não domiciliados foi considerado por $100 \%$ dos gestores de ONGs, $80,9 \%$ dos gestores de SCZs e $67,4 \%$ da população em geral. Somente $0,3 \%$ da população em geral considerou que os cães não domiciliados não representam nada. As diferenças encontradas entre todas as respostas de gestores de SCZs, gestores de ONGs e população são estatisticamente significativas $(\mathrm{p}<0,05)$. Esse sofrimento é uma realidade, pois os animais estão sujeitos à fome, falta de cuidado e de abrigo e a maus tratos, assunto este que será melhor discutido em seguida, quando for abordada a qualidade de vida destes animais.

Problemas associados ao excesso de cães soltos nas ruas da cidade são uma realidade e atingem os humanos e os próprios animais ${ }^{(3)}$. Pesquisa realizada em Canoas, RS, mostrou que, em levantamento realizado pelos agentes comunitários de saúde junto à comunidade, o principal problema encontrado foi o grande número de cães não domiciliados que agrediam e constrangiam os transeuntes, se envolviam em acidentes de trânsito e eram portadores ou reservatório de agentes biológicos causadores de enfermidades $^{23}$. Na Itália, em pesquisa desenvolvida por Slater et $\mathrm{al}^{(24)}, 90 \%$ dos entrevistados viam como um problema os cães não domiciliados, relacionando-os, ordenadamente, à segurança pessoal, seguida pela questão do bem-estar animal e da saúde pública.

Quando questionados sobre a responsabilidade pelo controle populacional de cães não domiciliados, 95,7\% dos gestores de SCZs e 92,9\% dos gestores de ONGs afirmaram que a responsabilidade era tanto do Poder Público como da sociedade. Concordaram com isto somente $63,8 \%$ da população em geral, grupo esse em que 23,5\% consideraram ser uma responsabilidade exclusiva do Poder Público, com o que concordaram somente $4,3 \%$ dos gestores de SCZs e 7,1\% dos gestores de ONGs. No grupo da população em geral, 7,8\% afirmaram ser esta uma responsabilidade exclusiva da sociedade. As diferenças encontradas entre as respostas de gestores de SCZs e gestores de ONGs não são estatisticamente significativas $(p>0,05)$, mas as diferenças encontradas entre estes e a população são 
estatisticamente significativas $(\mathrm{p}<0,05)$.

A grande maioria dos gestores, tanto de SCZs quanto de ONGs, concordou que a responsabilidade por resolver a questão dos cães não domiciliados envolve mais de um ator social, ou seja, diz respeito à sociedade e ao Poder Público. Observando-se a legislação vigente e os resultados de diversos trabalhos, percebe-se claramente que, por ser multifatorial, a resposta ao problema é interdisciplinar e deve ser dividida entre a sociedade, representada minimamente pelas ONGs de proteção animal, pelos médicos veterinários e pelos proprietários de animais, e o Poder Público, representado por seus órgãos de saúde pública, meio ambiente e trânsito ${ }^{(14,25-27)}$.

Interessante notar que a parcela da população em geral que concorda com este compartilhamento de responsabilidades é bem mais discreta quando comparada com os gestores de SCZs e ONGs. Em pesquisa realizada na Itália, a população apoiava que o governo e a comunidade tivessem responsabilidade em lidar com os cães não domiciliados ${ }^{(24)}$.

No que diz respeito à percepção da atuação das ONGs de proteção animal, nos municípios em que os gestores de SCZs conheciam alguma $\mathrm{ONG}, 2,1 \%$ consideravam que a mesma não realizava nenhuma ação visando ao controle populacional de cães não domiciliados, percepção que era a mesma para $1,6 \%$ da população em geral pesquisada. Para $8,5 \%$ dos gestores de SCZs, as ONGs eram parceiras do Poder Público municipal nestas atividades, com o qual concordava $2,3 \%$ da população em geral. Dos gestores de SCZs, 29,8\% consideravam que as ONGs atuavam de maneira independente do Poder Público, mas eram importantes no contexto do controle populacional, percepção com a qual concordava $10,4 \%$ da população. Já $4,3 \%$ dos gestores de SCZ e $2,1 \%$ da população em geral consideravam que as ONGs atuavam de maneira independente do Poder Público, mas não eram importantes no contexto do controle populacional. Importante notar que $68,2 \%$ da população em geral não soube responder a esta questão. As diferenças encontradas entre as respostas de gestores de ONGs e população são estatisticamente significativas $(\mathrm{p}<0,05)$.

Apesar de parcela considerável dos gestores de SCZ reconhecerem o papel das ONGs de proteção animal no contexto do controle populacional de cães não domiciliados, a grande maioria dos respondentes pertencentes à população em geral não considerava a ONG como importante neste contexto. As ONGs, juntamente com o Ministério Público, são instituições legítimas no Brasil para agir em favor dos animais enquanto sujeitos do direito sui generis que lhes é característico, de acordo com a condição de animais não humanos, que não podem se manifestar por si $\operatorname{mesmos}^{(3)}$.

A partir da década de 1980, as entidades de proteção aos animais começaram a exercer pressão sobre o Poder Público contra o recolhimento e posterior eutanásia de animais sadios não domiciliados e muitas iniciaram a instalação de abrigos para estes animais ${ }^{(30)}$. Historicamente, nos municípios que desenvolvem ações de controle populacional, o papel destas ONGs é importante, seja atuando isoladamente, seja como parceira do Poder Público, atuando como fiscalizadora e instigadora deste ${ }^{(28-30)}$. As $\mathrm{ONGs}$ podem ser colaboradoras valiosas, atuando nas áreas de educação e sensibilização da população para a guarda responsável, obtendo recursos para realizar diretamente o controle reprodutivo, municiando o Poder Público de informações sobre as populações de cães das

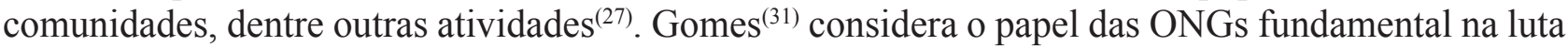
pelo Direito da Fauna Doméstica no Brasil, tendo em vista a carência de recursos estatais destinados a essa área.

Quando questionados sobre o destino que deve ser dado aos cães não domiciliados, como pode ser visualizado na Tabela 1, o recolhimento e doação dos cães não domiciliados foi a opção mais citada tanto pelos gestores de SCZs $(72,3 \%)$, pelos gestores de ONGs $(71,4 \%)$ e pela população em geral $(64,7 \%)$. O recolhimento seguido de esterilização e soltura nas ruas foi defendido por $71,4 \%$ dos gestores de ONGs e por 42,6\% dos gestores de SCZs mas só foi defendido por 4,4\% da população. O recolhimento e manutenção em canis foi defendido por 38,8\% da população, $25,5 \%$ dos gestores de SCZs e 21,4\% dos gestores de ONGs. O recolhimento seletivo de animais doentes e agressivos foi defendido por $28,6 \%$ dos gestores de SCZs e por $27,7 \%$ dos gestores de ONG mas somente por $3,6 \%$ da população. Já o recolhimento indiscriminado e posterior eutanásia foi defendido por $6,4 \%$ dos gestores de SCZ e por 2,1\% da população, mas não foi defendido por nenhum gestor de $\mathrm{ONG}$ 
de proteção animal, o que era esperado. As diferenças encontradas entre as respostas de gestores de SCZs, gestores de ONGs e população são estatisticamente significativas $(\mathrm{p}<0,05)$.

Tabela 1: Destino que deve ser dado aos cães não domiciliados segundo gestores de serviços de controle de zoonoses, gestores de ONGs de proteção animal e a população em geral, no Estado do Rio de Janeiro, Brasil

\begin{tabular}{lccccccc}
\hline & \multicolumn{2}{c}{$\begin{array}{c}\text { SERVIÇO DE } \\
\text { CONTROLE DE } \\
\text { ZOONOSES }\end{array}$} & ONG & \multicolumn{2}{c}{ POPULAÇÃO } \\
\multicolumn{1}{c}{ Destino } & N & \% & N & \% & N & \% \\
\hline $\begin{array}{l}\text { Deixá-los soltos nas ruas } \\
\text { Recolhimento indiscriminado e }\end{array}$ & 0 & 0 & 1 & 7,1 & 1 & 0,3 \\
eutanásia & 3 & 6,4 & 0 & 0 & 8 & 2,1 \\
$\begin{array}{l}\text { Recolhimento seletivo de doentes e } \\
\text { agressivos }\end{array}$ & 13 & 27,7 & 4 & 28,6 & 14 & 3,6 \\
$\begin{array}{l}\text { Recolhimento e manutenção em canis } \\
\text { Recolhimento, esterilização e soltura }\end{array}$ & 12 & 25,5 & 3 & 21,4 & 149 & 38,8 \\
nas ruas & 20 & 42,6 & 10 & 71,4 & 17 & 4,4 \\
$\begin{array}{l}\text { Recolhimento e doação } \\
\text { Outro }\end{array}$ & 34 & 72,3 & 10 & 71,4 & 244 & 63,5 \\
Não soube responder & 6 & 12,8 & 2 & 14,3 & 10 & 2,6 \\
& 0 & 0 & 1 & 7,1 & 11 & 2,9 \\
\hline
\end{tabular}

Apesar de a maioria dos entrevistados defender o recolhimento e posterior disponibilização para adoção dos animais não domiciliados como estratégia de controle populacional, somente $14,9 \%$ dos municípios a realizavam. Estudo realizado por Carvalho et al ${ }^{(32)}$ mostrou que $94 \%$ dos entrevistados citaram a adoção como solução para o problema dos cães não domiciliados, número bem acima do encontrado no presente trabalho. Os indivíduos têm diversas motivações para adotar um animal que vão desde experiências prévias com animais, passando por promessas, afetividade e, em especial, o impulso. Deve-se investir para evitar esta adoção por impulso para que a situação não leve a um possível novo abandono ${ }^{(33)}$.

Para Orlandi ${ }^{(34)}$, se os cães não domiciliados fossem capturados, vacinados contra a raiva, esterilizados e soltos novamente nas ruas, isso levaria à diminuição drástica da quantidade de cães soltos nas ruas, formando o que Paula ${ }^{(35)}$ classificou como 'barreira sanitária'. A OIE ${ }^{(27)}$ também recomenda a captura, tratamento veterinário, vacinação antirrábica e soltura na mesma região onde foi capturado, desde que tal situação seja aceita pela população local, o que, no presente estudo, só seria aceito por 4,4\% da população, apesar de bem aceito por parte dos gestores, principalmente os de ONGs. Importante notar que com a soltura destes animais não cessam os problemas envolvendo acidentes de trânsito, mordeduras e sujeira dos logradouros públicos pelos dejetos dos cães ${ }^{(27)}$. Neste contexto, há que se considerar ainda que, dependendo do estado de saúde e da imunidade do animal, a vacinação por si só não traz grande benefício sendo primordial o citado cuidado veterinário.

O recolhimento indiscriminado e posterior eutanásia, apesar de defendido por uma pequena quantidade de gestores de SCZs e da população em geral, é proibido pela Lei Estadual n ${ }^{\circ} 4808 / 2006^{(36)}$, que veda a eutanásia como método de controle populacional no Estado do Rio de Janeiro. Pesquisa realizada em São Paulo mostrou que 5,8\% da população era favorável à eutanásia dos cães recolhidos das ruas $^{(30)}$, proporção que representa quase três vezes a encontrada no presente estudo.

No que diz respeito à concordância com o gasto dos recursos destinados à saúde pública nas ações de controle populacional, em todos os grupos pesquisados a maioria concordou com esse gasto, sendo 
93,6\% dos gestores de SCZs, 92,9\% dos gestores de ONGs e 70,1\% da população em geral. Neste caso não houve diferença estatisticamente significativa entre as respostas dos gestores de SCZs e ONGs $(p>0,05)$, mas houve entre estes e as respostas da população $(p<0,05)$. Tradicionalmente, os recursos utilizados no controle de populações animais vêm do setor de saúde, tendo em vista a competência dos SCZs para com esta atividade ${ }^{(37)}$. Todavia, recentemente, o Ministério da Saúde, ao elencar as ações e serviços públicos de saúde voltados para a vigilância, prevenção e controle de zoonoses, determinou que ações, atividades e estratégias de controle de populações de animais somente devam ser executadas em situações excepcionais, por tempo definido, em áreas definidas e no intuito de controlar a propagação de zoonoses relevantes ${ }^{(38)}$.

$\mathrm{Na}$ avaliação da densidade populacional de cães não domiciliados, em todos os grupos pesquisados, uma grande parcela dos entrevistados considerou a densidade como grande, sendo 44,7\% dos gestores de SCZs, 85,7\% dos gestores de ONGs de proteção animal e 54,7\% da população em geral. A parcela que considerou a densidade populacional pequena também foi a menor em todos os grupos pesquisados, sendo 8,5\% dos gestores de SCZ, 7,1\% dos gestores de ONGs e 13,8\% da população em geral (Figura 1). As diferenças encontradas entre as respostas de gestores de SCZs, gestores de ONGs e população são estatisticamente significativas $(p<0,05)$.

Pesquisa realizada em Campo Grande, MS, mostrou que somente 23,6\% dos entrevistados afirmaram que costumavam ver nas ruas cães que provavelmente não tinham proprietário ${ }^{(39)}$. Já em um estudo realizado em Jaboticabal, SP, 92,8\% dos entrevistados afirmaram haver muitos animais soltos nas ruas $^{(32)}$, número consideravelmente superior aos encontrados para a categoria "grande densidade" na presente pesquisa, em especial se comparado com gestores de SCZs e com a população em geral. A densidade destes animais está interligada a fatores sócio-econômicos, os quais são característicos e peculiares nos diferentes grupos populacionais ${ }^{(4)}$. Tem-se que considerar que a densidade populacional de cães não domiciliados varia de região para região, ou seja, quanto pior for a condição social de uma região, maior tende a ser a sua população de cães não domiciliados ${ }^{(40,41)}$. $\mathrm{O}$ ambiente também vai influenciar já que, quanto maior a possibilidade de abrigo, água e alimentos, maiores serão as condições de sobrevivência e, consequentemente, maiores as populações nas ruas ${ }^{(4)}$. Logo, não se pode culpabilizar somente o abandono de animais pela superpopulação já que as questões ambientais, como a adequada coleta de lixo, também influenciam na densidade de animais ${ }^{(42)}$. A quantidade de habitantes do município também vai influenciar a densidade populacional, pois, quanto maior a quantidade de habitantes, maior o grau de restrição ao movimento dos cães, logo, diminui a quantidade de cães semi-domiciliados ${ }^{(43)}$ que, muitas vezes, são considerados pela população como não domiciliados em função da falta de coleira ou identificação e pela visualização contumaz nas ruas $^{(44)}$. Estudo de dimensionamento da população de cães no interior de São Paulo encontrou 32\% de cães semi-domiciliados ${ }^{(43)}$. Em pesquisa realizada em Botucatu, 53,7\% dos entrevistados afirmaram que seus cães tinham acesso è rua, sendo que $69,4 \%$ sozinhos $^{(45)}$. Em Curitiba, PR, quase $90 \%$ dos cães recolhidos das ruas eram semi-domiciliados ${ }^{(46)}$.

No que diz respeito à percepção sobre a qualidade de vida dos cães não domiciliados, grande parcela dos entrevistados concordava, em todos os grupos pesquisados, que a qualidade era péssima, sendo $38,3 \%$ dos gestores de SCZs, $35,7 \%$ dos gestores de ONGs e $65,1 \%$ da população em geral. Para $29,8 \%$ dos gestores de SCZs, $28,6 \%$ dos gestores de ONGs e $21,9 \%$ da população a qualidade de vida destes animais era ruim. Para $27,7 \%$ dos gestores de SCZ, 28,6\% dos gestores de ONGs e 9,6\% da população a qualidade de vida destes cães era razoável. Somente $2,1 \%$ dos gestores de SCZs, 7,1 $\%$ dos gestores de ONGs e $0,3 \%$ da população consideraram que a qualidade de vida dos cães não domiciliados era boa. Nenhum participante considerou excelente a qualidade de vida dos cães não domiciliados (Figura 2). Neste caso, não houve diferença estatisticamente significativa entre SCZs e ONGs ( $p>0,05)$, mas houve entre estes e a população $(p<0,05)$.

Dentre aqueles que consideraram o nível de qualidade de vida dos cães não domiciliados como péssimo, as principais justificativas foram (Figura 3): para os gestores de SCZs risco de adoecimento $(44,4 \%)$, deficiência alimentar $(38,9 \%)$ e maus-tratos e falta de cuidado e atenção $(22,2 \%)$; para os gestores de ONGs, deficiência alimentar (20\%) e outros (20\%); e para a população, deficiência de 
alimentos (43,2\%), outros motivos $(24,8 \%)$ e maus-tratos $(23,6 \%)$. As diferenças encontradas entre as respostas de gestores SCZs, gestores de ONGs e população são estatisticamente significativas $(\mathrm{p}<0,05)$.

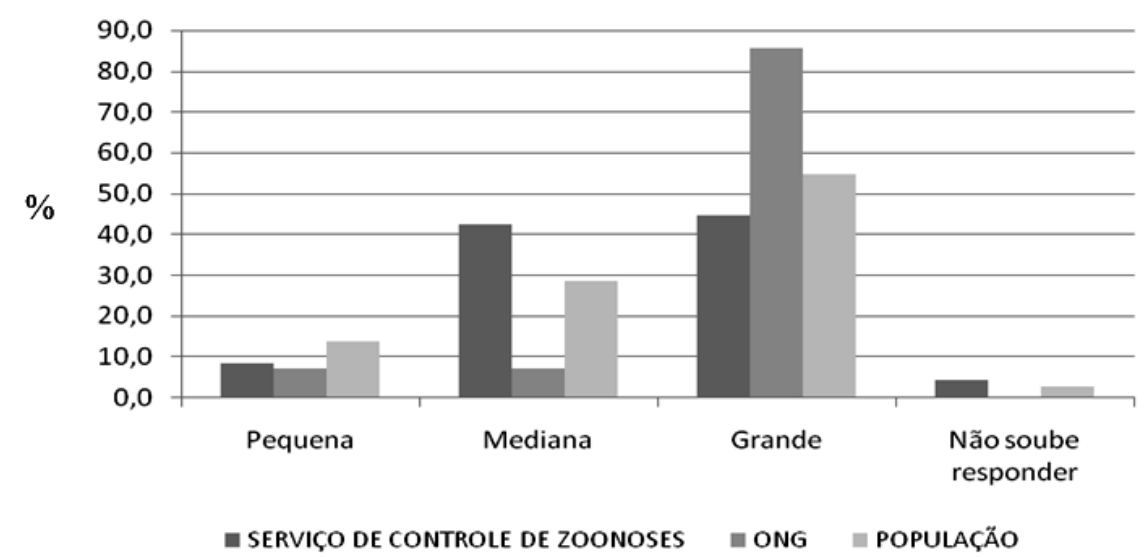

Figura 1: Opinião dos gestores de serviços de controle de zoonoses, dos gestores de ONG de proteção animal e da população em geral sobre a densidade populacional de cães não domiciliados, em seu local de residência/área de atuação, Estado do Rio de Janeiro, Brasil.

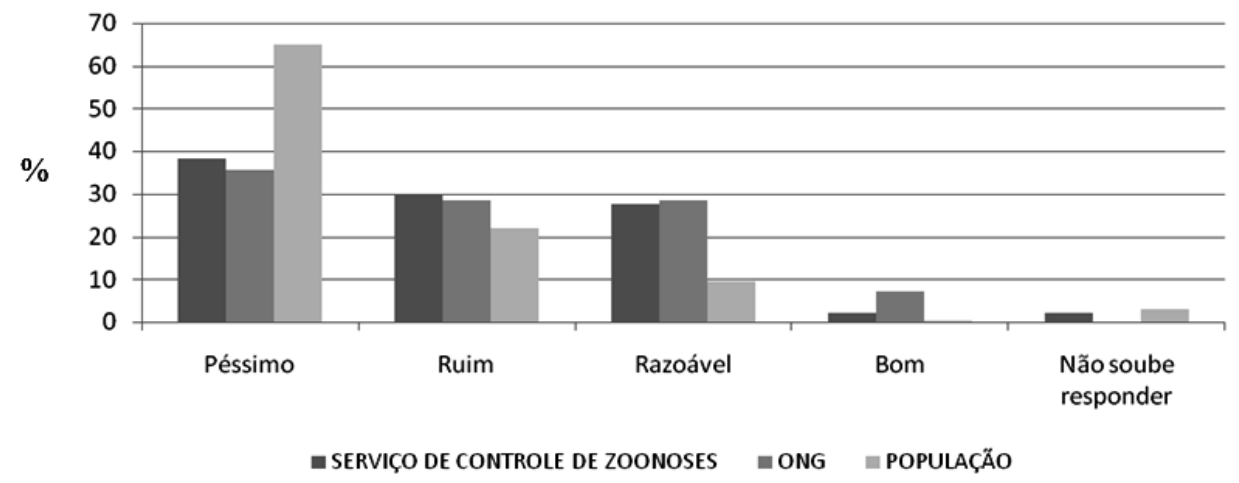

Figura 2: Nível de qualidade de vida dos cães não domiciliados segundo os gestores de serviços de controle de zoonoses, gestores de ONGs de proteção animal e população em geral, no Estado do Rio 


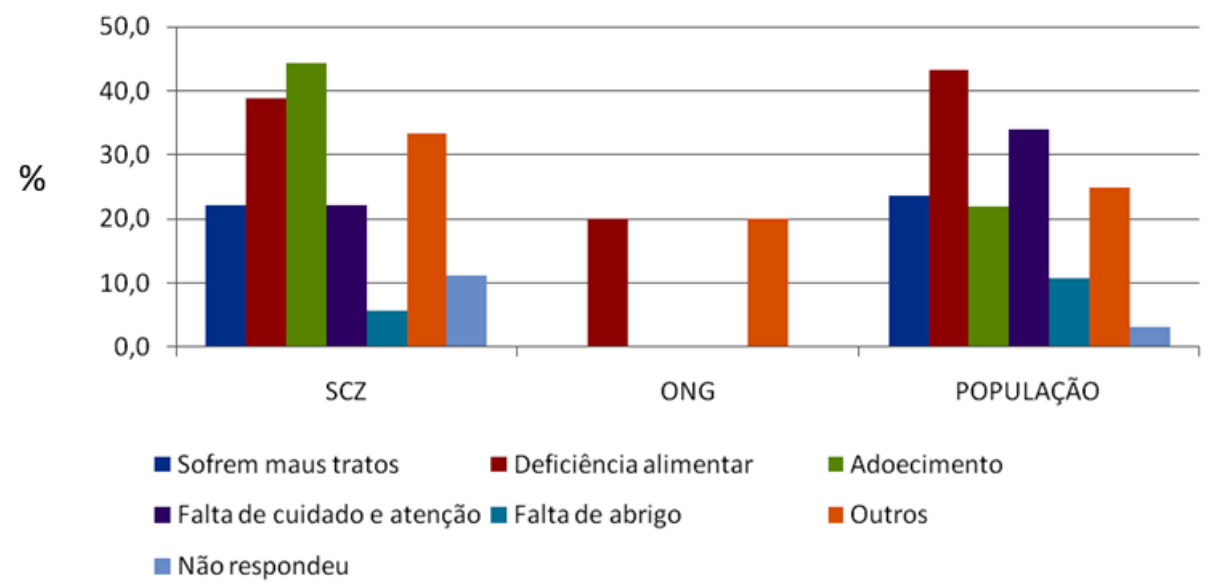

Figura 3: Motivos dos três grupos pesquisados para qualificar como péssima a qualidade de vida dos cães não domiciliados, Estado do Rio de Janeiro, Brasil.

Dentre aqueles que consideraram o nível de qualidade de vida dos cães não domiciliados como ruim, as principais justificativas foram (Figura 4): para os gestores de SCZs, risco de adoecimento (57,1\%), deficiência alimentar $(35,7 \%)$ e maus-tratos e falta de cuidado e atenção $(28,6 \%)$; para os gestores de ONGs, falta de cuidado e atenção (75\%), deficiência alimentar, risco de adoecimento e falta de abrigo (50\%) e maus-tratos (25\%); e para a população, falta de cuidado e atenção $(36,9 \%)$, deficiência de alimentos (33,3\%), adoecimento (29,8). Para 21,4\% dos gestores de SCZs, 25\% dos gestores de ONGs e 3,6\% da população, o nível de vida dos cães só não era péssimo pois parte da sociedade cuidava deles mesmo nas ruas. As diferenças encontradas entre as respostas de gestores SCZs, gestores de ONGs e população são estatisticamente significativas $(\mathrm{p}<0,05)$.

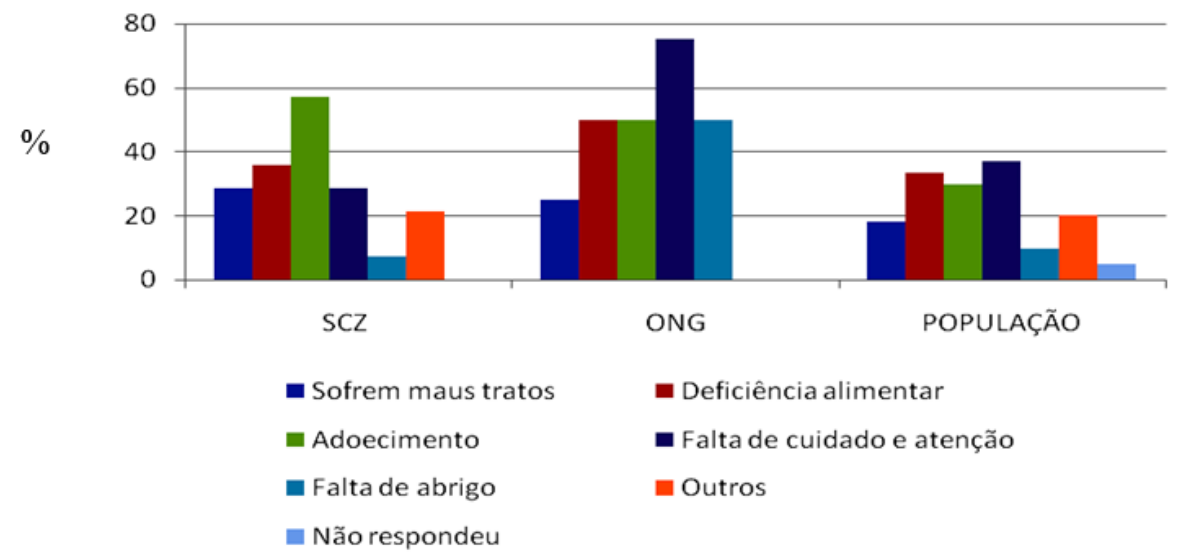

Figura 4: Motivos dos três grupos pesquisados para qualificar como ruim a qualidade de vida dos cães não domiciliados, Estado do Rio de Janeiro, Brasil.

Dentre aqueles que consideraram o nível de qualidade de vida dos cães não domiciliados como razoável (Figura 5), 53,8\% dos gestores de SCZs, 50\% dos gestores de ONGs e 37,8\% da população justificaram sua opção por considerarem que parte da sociedade cuidava destes animais mesmo nas ruas. As diferenças encontradas entre as respostas de gestores $\mathrm{SCZs}$, gestores de ONGs e população são estatisticamente significativas $(\mathrm{p}<0,05)$.

Todos os participantes que consideraram a qualidade de vida dos cães não domiciliados como boa 
(um de cada grupo pesquisado) justificaram sua opção por considerarem que parte da sociedade cuidava destes animais mesmo nas ruas.

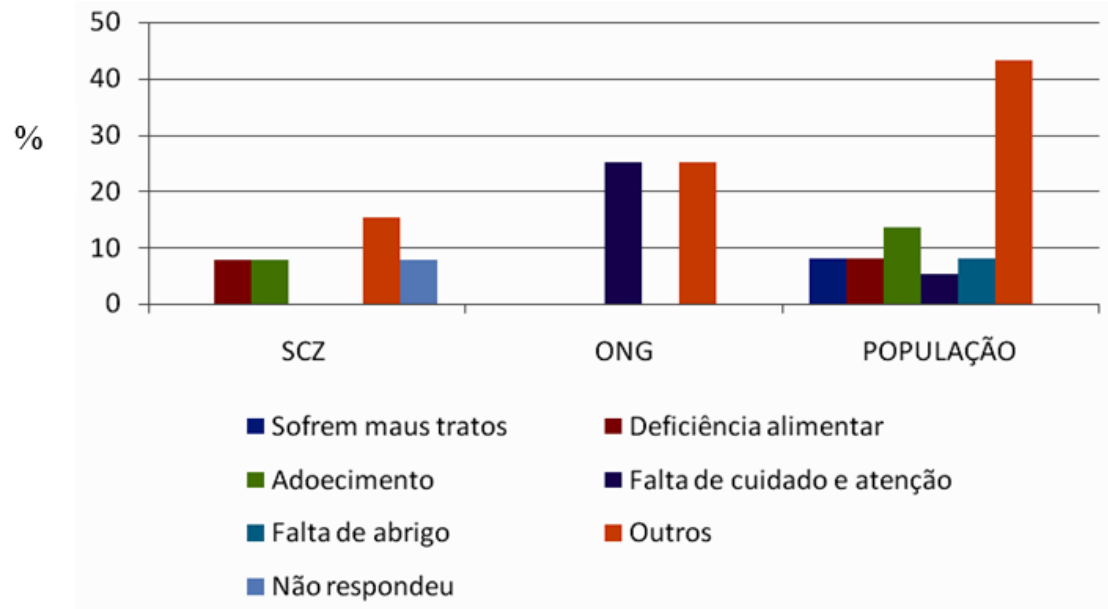

Figura 5: Motivos dos três grupos pesquisados para qualificar como razoável a qualidade de vida dos cães não domiciliados, Estado do Rio de Janeiro, Brasil.

É indubitável que o fato de o cão viver solto nas ruas e sem um guardião que zele por sua alimentação, abrigo e sanidade o coloca numa condição de vulnerabilidade que faz com que ele esteja sujeito a uma série de adversidades, como maus-tratos, fome, frio, medo, riscos à sua saúde (biológicos e não biológicos), dentre outros fatores.

O sofrimento das ruas reflete no organismo do animal como um todo, reduzindo sua imunidade, já que o animal sofre deficiência nutricional, estresse e tristeza, o que culmina com o adoecimento e a transmissão de zoonoses ${ }^{(11)}$. Os resultados obtidos estão de acordo com Rosa Júnior et al. ${ }^{(47)}$, para quem a superpopulação de cães favorece a transmissão de zoonoses e a contaminação ambiental por dejetos. Além disso, os cães ficam expostos a atropelamentos, brigas e doenças. Estudos que tratam das condições de saúde dos cães vêm demonstrando a importância das doenças infecciosas como agentes de morbidade e mortalidade para estes animais ${ }^{(48,49)}$.

A questão dos maus tratos também foi abordada por parcela considerável dos respondentes que consideravam a qualidade de vida dos animais não domiciliados como péssima e ruim. As agressões e violências contra os animais são comuns na sociedade, pelo desconhecimento da condição de ser senciente destes, que sentem, sofrem e têm necessidades e direitos ${ }^{(14)}$. Em pesquisa realizada na Itália, a população entrevistada mostrou grande preocupação com a questão do bem-estar dos cães não domiciliados, que sofrem maus tratos e têm necessidades ${ }^{(24)}$. Importante salientar que a própria possibilidade de transmissão de zoonoses pode ser um fator desencadeante dos maus-tratos, logo, é importante demonstrar que há um efetivo controle de doenças nos animais comunitários, com o uso de coleiras, por exemplo ${ }^{(16)}$, para diminuir o risco de a população maltratar esses animais.

Importante parcela dos respondentes atribuiu uma qualidade de vida razoável ou boa aos cães não domiciliados pelo fato de estes receberem cuidados de cidadãos ou de ONGs de proteção animal. A maioria dos cães não domiciliados tem, no mínimo, uma pessoa que lhe fornece, ainda que inadequadamente, alimentação e abrigo ${ }^{(50)}$. Em pesquisa realizada em Campo Grande, MS, $14 \%$ dos entrevistados afirmaram alimentar cães não domiciliados ${ }^{(39)}$. Em São Paulo, SP, 2,42\% dos residentes entrevistados afirmaram cuidar de cães de rua ${ }^{(42)}$.

Os motivos que levam as pessoas a alimentar animais de rua variam de local para local ${ }^{(16)}$. Importante notar que aqueles cuidadores que têm cães em casa podem atuar como carreadores de patógenos dos cães comunitários para os seus ${ }^{(42)}$. Mas há pesquisadores que são críticos do que eles denominam de 'proprietários não assumidos', que oferecem cuidados parciais aos animais não domiciliados, mas, segundo eles, concentram um foco de proliferação animal antinatural, passando um entendimento de 
que ali podem ser abandonados animais sem que isso gere maiores consequências, pois são cuidados pelas pessoas ${ }^{(50)}$. Esta preocupação pode ter fundamento, mas quando não há alternativa, o animal comunitário, se aceito pela população local, pode ser uma saída. Importante que o cuidado dispensado a ele não se restrinja ao fornecimento de alimento, mas envolva, também, cuidados veterinários. Como estes animais são aceitos pela população que não os vêm como ameaça, ocorre um contato mais íntimo e mais expansivo, aumentando o risco de transmissão de zoonoses; reforça-se, assim, a necessidade de ações educativas com estes cuidadores ${ }^{(42)}$.

Toda esta discussão acerca da qualidade de vida dos cães não domiciliados encontra respaldo na questão do conceito de bem-estar animal, que se relaciona necessariamente com conceitos como necessidades, felicidade, liberdades, sentimentos, sofrimento, medo, ansiedade, dor, estresse e tédio, dentre outros ${ }^{(51)}$. Está relacionada, também, às cinco liberdades, as quais possibilitam o bem-estar animal, por defender que eles sejam mantidos livres de fome e sede, de desconforto físico e dor, de injúrias ou doenças, de medo ou estresse e livres também para que manifestem seus padrões característicos de comportamento ${ }^{(2)}$.

\section{Conclusões}

Os resultados auferidos permitem concluir que havia grande diferença na distribuição das ONGs de proteção animal entre as Regiões de Saúde do estado do Rio de Janeiro e, de modo geral, a percepção da sociedade sobre o controle populacional de cães não domiciliados e a qualidade de vida desses animais guardam expressivas diferenças sob a ótica dos três grupos de atores sociais avaliados, mas apresentam, também, semelhanças importantes, em especial no tocante à percepção sobre a responsabilidade pelo desenvolvimento de ações de controle populacional, à aceitação da utilização de recursos públicos destinados à saúde pública nas ações de controle populacional, à qualificação como grande à densidade de cães não domiciliados e à má qualidade de vida desses animais.

\section{Referências}

1. Silva MHS, Silva JA, Magalhães DF, Silva MX, Meneses JNC, Moreira EC. Caracterização demográfica e epidemiológica de cães e gatos domiciliados em Barbacena, MG. Arquivos Brasileiros de Medicina Veterinária e Zootecnia. 2010;62(4):1001-1006.

2. Silvano D, Bendas AJR, Miranda MGN, Pinhão R, Mendes de Almeida F, Labarthe NV, Paiva JP. Divulgação dos princípios de guarda responsável: uma vertente possível no trabalho de pesquisa a campo. Revista Eletrônica Novo Enfoque. 2010;9(9):64-86.

3. Vieira AML, Almeida AB, Magnabosco C,Ferreira JCP, Luna SLP, Carvalho JLB, Gomes LH, Paranhos NT, Reichmann ML, Garcia RC, Nunes VFP, Cabral VB. Programa de controle de cães e gatos do Estado de São Paulo. BEPA [periódico na Internet]. 2006;3(25). [cited 2012 Fev 22]. Disponível em http://www.cve.saude. sp.gov.br/agencia/bepa25 rg7caes.htm.

4. Reichmann MLAB, Figueiredo ACC, Pinto HBF, Nunes VFP. Controle de populações de animais de estimação. São Paulo: Instituo Pasteur, 2000. 2009 [cited 2014 Jun 05]. Disponível em http://www.saude. sp.gov.br/resources/instituto-pasteur/pdf/manuais/manual_06.pdf.

5. Garcia RCM, Maldonado NAC, Lombardi A. Controle populacional de cães e gatos. Ciências veterinárias nos trópicos; 2008;11(1):106-110.

6. Thrusfield M. Epidemiologia veterinária. 2. ed. São Paulo: Roca, 2004. 556 p.

7. Rio de Janeiro. Secretaria de Estado de Saúde. Plano Diretor de Regionalização: Secretaria de Estado de Saúde, 2001. [cited 2009 Jun 02]. Disponível em http://www.saude.rj.gov.br/docman/informes-ao-gestor/ planejamento/pas/10749-plano-diretor-de-regionalizacao-2001-2004/file.html.

8. Comissão Intergestores Bipartite. Deliberação n753/2009. Constituição do Comitê Gestor Regional da Capital. 2009 [cited 2014 Jun 05]. Disponível em http://www.cib.rj.gov.br/deliberacoes-cib/104-2009/ novembro/593-deliberacao-cib-no-0753-de-13-de-novembro-de-2009.html .

9. Instituto Brasileiro de Geografia e Estatística. As fundações privadas e associações sem fins lucrativos no Brasil 2010. Estudos e pesquisas econômicas, n. 20. Rio de Janeiro: IBGE, 2012. [cited 2014 Jun 05]. 
Disponível em ftp://ftp.ibge.gov.br/Fundacoes_Privadas_e_Associacoes/2010/fasfil.pdf.

10. Instituto Brasileiro de Geografia e Estatística. Fundações privadas e associações sem fins lucrativos no Brasil em 2010. Número de unidades locais das entidades sem fins lucrativos, por grupos da classificação das entidades sem fins lucrativos - 08 meio ambiente e proteção animal. Comparação entre os municípios: Rio de Janeiro. 2013 [cited 2014 Jan 09]. Disponível em http://cod.ibge.gov.br/15RKG.

11. Paula SA. Política Pública de esterilização cirúrgica de animais domésticos, como estratégia de saúde e de educação. Monografia (Especialização) Pós-Graduação em Gestão Publica Municipal. Medianeira: UTFP, 2012. 40 p. 2012 [cited 2014 Jun 14]. Disponível em http://repositorio.roca.utfpr.edu.br/jspui/bitstream/1/1495/1/ CT GPM II 2012 32.pdf.

12. Garcia RCM. Estudo da dinâmica populacional canina e felina e avaliação de ações para o equilíbrio dessas populações em áreas da cidade de São Paulo, SP, Brasil. Tese (Doutorado) Programa de Pós-Graduação em Epidemiologia Experimental Aplicada às Zoonoses. São Paulo: USP, 2009. 265 p. 2009 [cited 2014 Jun 14]. Disponível em http://www.teses.usp.br/teses/disponiveis/10/10134/tde-18012010-154127/pt-br.php.

13. Garcia RC, Maldonado N, Ferreira F. Consolidação de diretrizes internacionais de manejo de populações caninas em áreas urbanas e proposta de indicadores para seu gerenciamento. Revista Panamericana Salud Publica. 2012;32(2):140-144.

14. Santana LR; Oliveira TP. Guarda Responsável e Dignidade dos Animais. Revista Brasileira de Direito Animal. 2006;1(1):67-105.

15. Miranda CFJ, Silva JA, Moreira EC. Raiva humana transmitida por cães: áreas de risco em Minas Gerais, Brasil, 1991-1999. Cadernos de Saúde Pública. 2003;19(1):91-99.

16. International Companion Animal Management - ICAM. Guia de controle humanitário da população canina. 2007 [cited 2013 Jul 23]. Disponível em http://www.icam-coalition.org/downloads/Humane Dog Population_Management_Guidance_Portuguese.pdf.

17. Food and Agriculture Organization. World Livestock 2013 - Changing disease landscapes. Rome: FAO, 2013. [cited 2014 Jan 23]. Disponível em http://www.fao.org/docrep/019/i3440e/i3440e.pdf.

18. Taylor LH, Latham SM, Woolhouse ME. Risk factors for disease emergence. Philosophical Transactions of the Royal Society B. 2001;(356):983-989.

19. Frias DFR, Nunes JOR, Carvalho AB. Caracterização de agravos causados por cães e gatos a seres humanos no município de Jaboticabal, São Paulo, durante o período de 2000 a 2009. Archives of Veterinary Science. 2012;17(3):63-70.

20. Rodrigues RCA, Polo G, Castagna CL Pressoto D, Baquero OS, Baldini MBD, Pisciotta KR, Lantzman M, Dias RA. Caracterização de casos de agressão canina em Campinas, São Paulo, Brasil. Brazilian Journal of Veterinary Research and Animal Science. 2013;50(3):233-237.

21. Fortes FS, Wouk AFPF, Biondo AW, Barros CC. Acidentes por mordedura de cães e gatos no município de Pinhais, Brasil, de 2002 a 2005. Archives of veterinary science. 2007;12(2):16-24.

22. Oliveira VMR, Pereira PLL, Silva JA, Miranda CFJ, Rodrigues KO, Moreira EC. Mordedura canina e atendimento antirrábico humano em Minas Gerais. Arquivos Brasileiros de Medicina Veterinária e Zootecnia. 2012;64(4):891-898.

23. Teixeira EP; Halla R. O centro de controle de zoonoses e os agentes comunitários: a experiência de Canoas 2002/2003. Boletim da saúde. 2004;18(1):191-194.

24. Slater MR, Di Nardo A, Pediconi O, Villa PD, Candeloro L, Alessandrini B, Del Papa S. Free-roaming dogs and cats in central Italy: public perceptions of the problem. Preventive Veterinary Medicine. 2008;84:2747.

25. Bortoloti R; D’agostino RG. Ações pelo controle reprodutivo e posse responsável de animais domésticos interpretadas à luz do conceito de metacontingência. Revista brasileira de análise do comportamento. 2007;3(1):17-28.

26. Lima FM, Luna SPL. Algumas causas e consequências da superpopulação canina e felina: acaso ou descaso? Revista de educação continuada em medicina veterinária e zootecnia do CRMV-SP. 2012;10(1):32-38.

27. Organização Internacional de Saúde Animal - OIE. Control de las poblaciones de perros vagabundos. In: OIE. Código Sanitario para los Animales Terrestres - 2013. 2013 [cited 2013 Out 22]. Disponível em: http:// www.oie.int/es/normas-internacionales/codigo-terrestre/acceso-en-linea/.

28. Castro MS. A evolução dos direitos animais em Florianópolis. Revista Santa Catarina em História. 2011;5(2):103-116.

29. Lui JF, Toniollo GH, Savi PAP, Voorwald FA, Silva MAM, Tosta PA. Esterilização cirúrgica de caninos e 
felinos em Jaboticabal. Interação entre o benefício social e a pesquisa científica. Revista Ciência em Extensão. 2011;7(2):33.

30. Souza M FA. Controle de populações caninas: considerações técnicas e éticas. Revista Brasileira de Direito Animal. 2011; 8(6):115-133.

31. Gomes NSC. Uma perspectiva da construção dos direitos da fauna doméstica do município de Belo Horizonte - MG. Revista Brasileira de Direito Animal. 2010; 5(7):285-305.

32. Carvalho AAB, Grisólio APR, Bueno GM, Testi AJP, Martins MC, Portela LC, Servidone JS, Nunes JOR. Caracterização da população de cães e gatos e avaliação do nível de conhecimento dos moradores sobre zoonoses e posse responsável de animais de estimação em bairros do município de Jaboticabal / SP. Revista Ciência em Extensão. 2011;7(2):158-159.

33. Paploski IAD, Babboni SD, González GK, Giarola RM, Rodrigues SA, Cerqueira ATAR, Padovani $\mathrm{CR}$, Victória C, Modolo JR. Características dos adotantes de cães na área urbana de Botucatu. Veterinária e Zootecnia. 2012;19(4):584-592.

34.Orlandi VT. Da eliminação de animais em Centros de Controle de Zoonoses. Revista Brasileira de Direito Animal. 2011;6(8):135-160.

35. Paula PMC. Estratégias adicionais no controle populacional de cães de rua. Dissertação (Mestrado). Programa de Pós-Graduação em Ciências Veterinárias. Curitiba: UFPR, 2010, 71 p. [cited 2013 Out

12]. Disponível em http://dspace.c3sl.ufpr.br/dspace/bitstream/handle/1884/23726/ESTRATEGIAS\%20 ADICIONAIS\%20NO\%20CONTROLE\%20POPULACIONAL\%20DE\%20CAES\%20DE\%20RUA. pdf? sequence $=1$.

36. Rio de Janeiro. Lei $\mathrm{n}^{\mathrm{o}} 4.808$ de 04 de julho de 2006. Dispõe sobre a criação, a propriedade, a posse, a guarda, o uso, o transporte e a presença temporária ou permanente de cães e gatos no âmbito do estado do Rio de Janeiro. [cited 2010 Jul 24]. Disponível em http://alerjln1.alerj.rj.gov.br/contLei.nsf/ c8aa0900025feef6032564ec0060dfff/6628191723549496832571a8005e8896? opendocument.

37. Reichmann MLAB, Sandoval MRC, Formaggia DME, Presotto D, Nunes VFP, Santos LS, Glasser CM, Costa MAF. Orientação para projetos de Centros de Controle de Zoonoses (CCZ). 2 ed. São Paulo: Instituto Pasteur, 2000 [cited 2013 Out 10]. Disponível em http://www.saude.sp.gov.br/resources/instituto-pasteur/pdf/ manuais/manual 02.pdf.

38. Brasil. Ministério da Saúde. Portaria $n^{\circ} 1.138$, de 23 de maio de 2014. Define as ações e os serviços de saúde voltados para vigilância, prevenção e controle de zoonoses e de acidentes causados por animais peçonhentos e venenosos, de relevância para a saúde pública. 2014 [cited 2014 Jun 14]. Disponível em http:// www.brasilsus.com.br/legislacoes/gm/124005-1138.html.

39. Domingos IH, Rigo L, Honer MR. Perfil da populações canina e felina no município de Campo Grande, MS. Ensaios e ciência. 2007;11(1):97-103.

40. Ávila-Pires FD. Zoonoses: hospedeiros e reservatórios. Cadernos de Saúde Pública. 1989;5(1):82-97.

41. Shimozako HJ, Amaku M, Ferreira F, Dias RA, Netto HM, Paranhos NT, Dias RB. Uso de sistemas de informação geográfica como ferramentas de auxílio na análise de casos de apreensão de animais no município de São Paulo. Revista Ciência em Extensão. 2006;2(2):1-16.

42. Magnabosco, C. População domiciliada de cães e gatos no Município de São Paulo: perfil obtido através de um inquérito multicêntrico. Dissertação (Mestrado). Faculdade de Saúde Pública. São Paulo: USP, 2006. 110 p. 2006 [cited 2014 Jun 15]. Disponível em http://www.teses.usp.br/teses/disponiveis/6/6132/tde-06032007104453/pt-br.php.

43. Alves MCGP, Matos MR, Reichmann ML, Dominguéz MH. Dimensionamento da população de cães e gatos do interior do Estado de São Paulo. Revista de Saúde Pública. 2005; 39(6):891-897.

44. Canatto BD, Silva EA, Bernardi F, Mendes MCNC, Paranhos NT, Dias RA. Caracterização demográfica das populações de cães e gatos supervisionados do município de São Paulo. Arquivos Brasileiros Medicina Veterinária e Zootecnia. 2012;64(6):1515-1523.

45. Langoni H, Troncarelli MZ, Rodrigues EC, Nunes HRC, Harumi V, Henriques MV, Silva KM, Shimono JY. Conhecimento da população de Botucatu - SP sobre Guarda Responsável de cães e gatos. Veterinária e Zootecnia. 2011;18(2):297-305.

46. Biondo AW, Cunha GR, Silva MAG, Fuji KY, Utime RA, Molento CFM. Carrocinha não resolve. Revista do Conselho Regional de Medicina Veterinária - PR. 2007;5(25):20-21.

47. Rosa Júnior AS, Araújo MD, Añaña DC, Batista M, Acosta GS, Guterres KA, Athaide C, Stelmake LL, Cleff MB. Medicina veterinária na promoção da saúde humana e animal: ações em comunidades carentes como estratégias de enfrentamento da desigualdade social. Revista Ciência em Extensão. 2012;8(3):278-283. 
48. Bentubo HDL, Tomaz MA, Bondan EF, Lallo MA. Expectativa de vida e causas de morte em cães na área metropolitana de São Paulo (Brasil). Ciência Rural. 2007;37(4):1021-1026.

49. Neufeld AB. Fatores de mortalidade em cães no município de Paraty - RJ. Revista Controle Biológico (BE-300) on-line. 2010;2:9-12. Disponível em http://www2.ib.unicamp.br/profs/eco_aplicada/revistas/ be300 vol2 3.pdf.

50. Oliveira DM.; Silva MC. Sobre animais abandonados e pessoas que lidam com eles: o papel dos clínicos veterinários. Revista Brasileira de higiene e sanidade animal. 2008;2(4):56-79.

51. Broom DM; Molento CFM. Bem-estar animal: conceito e questões relacionadas - revisão. Archives of Veterinary Science. 2004;9(2):1-11. 